\title{
Enabling students to lead the way Healthy lifestyles and healthy futures
}

\author{
SALLY BOYD
}

\section{KEY POINTS}

- The new curriculum signals and supports a new approach, where students learn by taking action on real-life issues. This meshes with recent ideas about encouraging people to be healthy by giving them skills to address the factors around them that might discourage healthy behaviour.

- This study showed that the Fruit in Schools initiative encouraged schools to create a healthy school culture by promoting student-led health projects, including healthy lunch days, fundraising for water fountains, running lunchtime sports or promoting new sports equipment.

- These projects empowered students, helped them understand and value healthy behaviour, improved their engagement with school and developed their life skills and competencies.

- The results suggest that this creates a "protective climate"nurturing healthy kids who are positive about school and less likely to engage in risky behaviour in the future.

- Implementing the student-led projects required teachers to make a "mindshift" in giving power to students, and to work to support students to ensure their success. 


\section{This article makes connections between the findings from an evaluation of the Ministry of Health's Fruit in Schools (FiS) initiative and recent changes in the New Zealand curriculum, in particular in the Health and Physical Education (PE) learning area. It explores the rationale for actively involving students in health promotion at school, describes a range of student-led activities that are connected to the Health and PE learning area and explores some of the benefits and challenges of sharing decision making with students.}

\section{Introduction}

This is the first of two articles about school approaches to health and wellbeing. This article explores some of the benefits of student-led actions related to health and wellbeing, and the second article discusses the use of whole-school approaches to health and wellbeing. These articles make connections between the findings from an evaluation of the Ministry of Health's FiS initiative and recent changes in the New Zealand curriculum, in particular, in the Health and PE learning area. They describe some of the actions and experiences of staff and students at six case study primary schools and also draw on the findings from surveys of students and staff at FiS and comparison schools.

FiS has a number of components. Perhaps the most well known is that the low-decile schools in the initiative are provided with a daily piece of fruit for each student. FiS schools are also offered extra support to use the Health Promoting Schools approach to develop local ways of promoting healthy lifestyles in ways that involve students, parents and whānau and school staff. This approach is discussed in more depth in the companion article. Schools also receive extra funding for release time for a FiS lead teacher, and assistance from FiS co-ordinators and health agencies, to encourage the promotion of four priority areas: healthy eating, physical activity, being sunsmart and being smokefree.

\section{Shifts in practice in the revised}

\section{curriculum}

The recent revision of the entire curriculum (Ministry of Education, 2007b) places an increased emphasis on schools designing a curriculum that is responsive to the local community and student interests and is structured around future-focused and significant issues such as sustainability and citizenship. The revised curriculum also places more emphasis on student decision making, studentcentred practice and lifelong learning. In the round of curriculum development prior to the 2007 revision, the 1999 Health and PE curriculum was one of the last areas to be developed, and therefore many of these newer ideas were already evident in this earlier document.

Aitken (2006) argues that there is a need for curriculum policy to signal shifts in meaning which occur when curricula are revised. These signals need to enable teachers to see how reforms build on, as well as change, past practice. Otherwise, there is a risk that the intention of curriculum documents will be misconstrued. So, what are the implications of the wider revision of the curriculum for teaching and school-wide practice in the Health and PE learning area?

One of the big changes signalled in the new curriculum is in approaches to the "how" of learning. The revised curriculum places more emphasis on involving students and the wider community in decision making about learning, and on students "doing something" with knowledge through being "active seekers, users, and creators of knowledge" (Ministry of Education, 2007b, p. 8). That is, there is an expectation that students will learn through exploring and taking action in regard to real-life issues that are relevant to them and their wider community, as they "contribute to the development and well-being of society" (Ministry of Education, 2007b, p. 39). The idea of students taking action is discussed in the newer parts of the curriculum, for example, in the vision statement and the section on key competencies, as well as within the revised parts, such as the Health and PE learning area. In Health and PE, this emphasis on student-led action is exemplified in one of the underlying concepts. This is the need for students to engage in health promotion, which is defined as:

... a process that helps to develop and maintain supportive physical and emotional environments and that involves students in personal and collective action. (Ministry of Education, 2007b, p. 22) 


\section{Changing views about health and wellbeing}

The above definition of health promotion clearly positions students as active participants and is based on "societal" approaches to health and wellbeing. Societal approaches emphasise that an individual's capacity for change is affected not only by their health knowledge and beliefs but also by the social and physical environment in which they live. The emphasis on societal approaches in The New Zealand Curriculum is related to a key shift that occurred in the health sector in the 1980s. This was a move away from the previous "individual" view of health. Individual and societal approaches are based on different views about what it is to be healthy (Lister-Sharp, Chapman, Stewart-Brown, \& Sowden, 1999). Individual approaches prioritise physical health and are underpinned by an assumption that individuals have full control over their health-related behaviours. They assume that giving information about health risks will result in healthy lifestyles. In terms of educational activities, individual approaches tend to emphasise students "learning about" health.

In contrast, the societal view is holistic and encompasses physical, spiritual, social and emotional health and wellbeing. This holistic view of health and wellbeing underpins te Whare Tapa Whā model of hauora developed by Mason Durie (Ministry of Education, 1999). ${ }^{1}$ This model is one of the four concepts at the heart of the Health and PE learning area. Societal and holistic views of health and wellbeing, and the definition of health promotion in The New Zealand Curriculum, are founded on the idea that students (and communities) need to do more than "learn about" an aspect of health by being the recipients of health information; they also need to be able to understand and critically evaluate the interconnecting factors that affect health and wellbeing (Tasker, 2004), and develop skills and competencies for the future as they "learn for their health" by "learning by doing" health-promotion activities that address barriers to health and wellbeing and improve their environment. The Health and PE learning area strand that most directly encompasses these ideas is Healthy Communities and Environments. Seen in terms of the revised curriculum, this means we are educating students to be active citizens now, as well as supporting them to develop the knowledge, skills and dispositions that will prepare them for the future.

So what could "learning for health" look like in a school setting, and what impact does this have on students' and teachers' roles and experiences?

\section{Involving students in school-wide decisions}

The big picture at many FiS schools was about creating a "healthy school" culture. One aim of this was to support students to enhance their ability to make healthy choices. These choices could be related to the four health priority areas that are part of FiS, or other aspects of health, such as social and emotional wellbeing. One way schools did this was by setting up new opportunities and processes for students to have input into school decisions and actions and lead health-related activities. This type of active student involvement is advocated by the Health Promoting Schools approach used by FiS schools.

So how is this different from what is already happening in schools? Many New Zealand primary schools already offer students a range of opportunities to be role models or leaders. These include being a school council representative; Year 6 or Year 8 leader; class leader; cultural leader; or peer, buddy or tuākana-tēina partner. Some schools are also developing new specialist roles for students, such as student curriculum team members, or ICT support for teachers or students. There are also student leadership opportunities connected to health and PE. These include roles as peer mediators, sports team leaders or junior coaches.

Our data showed that, over time, FiS schools were increasingly setting up opportunities for students to be role models and leaders in relation to health and wellbeing (Boyd \& Moss, 2009). This tended to occur at a school-wide level rather than within the classroom programme. Along with monitors who distributed the FiS fruit, there were two main new forms of student-led opportunities at FiS schools, which are described below.

\section{Student health teams}

Most FiS schools set up health teams. These teams were in two main forms. Some schools had teams which included representation from staff, students, parents and whānau. Other schools had student-led teams. These teams could be composed of students from one class or students from different classes. These students worked together, and with teachers or local health promoters, to develop ways to promote health and wellbeing in their school. They used ideas about health promotion processes $^{2}$ to develop priorities. That is, they:

- engaged in awareness-raising activities, such as promoting their role and healthy lifestyles to their community at assemblies, or through developing PowerPoints, DVDs or newsletter articles

- identified needs by brainstorming ideas and getting input from other students through surveys, suggestion boxes and discussion 
- selected priorities that fitted with wider school plans

- developed plans and organised a range of activities. Promoting healthy eating was the most common focus of these teams. Students contributed to a wide range of activities which included: planning school and community events that modelled healthy eating, such as healthy roll or soup lunch days; running competitions and "caught being healthy" awards; improving access to drinking water by conducting an audit of existing sources and fundraising for new water fountains; surveying students to gather their views on healthier options for school lunch food and then working with canteen staff to change menus; assisting staff to develop healthy eating policies; preparing booklets for parents that displayed quick and healthy lunch options; filming students for a DVD that was shown at assembly to present health messages in an entertaining format and showcase the healthy activities happening in different classes; and writing articles with health tips for the school newsletter. Students also promoted their activities and reported on their progress to other students, parents and whānau and the board of trustees.

\section{Promoters of physical activity}

Another common practice at FiS schools was to have a team of students who contributed to the school's physical activity focus. Some of these students were trained as Physical Activity Leaders (PALs) by Active Schools facilitators from regional sports trusts: others were selected and supported by school staff. These student teams engaged in activities such as: developing and running lunchtime games or activities such as Jump-Jam for other students; surveying students about the sports equipment to which they would like access; introducing and promoting new sports equipment at assembly; managing access to sports equipment at break times; and assisting in organising physical activities at community events and fundraisers. Some student teams also consulted other students about ways the school physical environment could be enhanced. They developed plans to improve playground markings, or make the school hall more accessible for students who wanted to practise dance performances or play indoor sports.

\section{Seeing the connection with other aspects of health and wellbeing}

Along with new forms of student-led activities, nearly all of the case study schools made connections between healthy lifestyles and the health of the environment, and they did this in ways that strengthened both focuses. Student teams contributed to environmental actions that were related to the FiS health areas. These included developing edible gardens and using these as a vehicle to promote healthy eating, using the FiS fruit scraps for worm farms and compost systems for their garden or planting trees and orchards for shade and fruit supply. Some also strengthened a zero-waste focus by doing composting, recycling or holding zero-waste lunchbox events. These activities were also connected to the school's focus on healthy eating. At some schools, FiS added value to the actions of an existing Enviroschools team, and students worked with a facilitator to develop a vision for their school that encompassed the health and wellbeing of the people in the school community as well as the physical environment. Other schools were in the process of joining Enviroschools.

A number of school leaders also saw that offering an increased range of student leadership and role modelling opportunities was contributing to students' self-esteem and skills in relating to others. This was encouraging school leaders to consider further ways that students could actively contribute to improving the social and emotional climate at their school.

\section{Who supported the student teams?}

These teams and leadership roles connected students with a range of other students and adults. Many of the health teams gained ideas from other schools through their attendance at regional student leadership workshops. These were organised by FiS co-ordinators and Health Promoting Schools advisers from local health agencies. Student health teams were also supported by school staff, including lead teachers, school leaders and teaching assistants, and in some cases by local FiS co-ordinators or Active Schools facilitators. Some had parent or whānau support. Enviroschools groups were assisted by teachers and Enviroschools facilitators. School staff also facilitated connections with resource people who could assist students. These people included public health nurses, nutritionists, local recycling experts and business people.

\section{What did students gain from taking a lead role?}

\section{Students' perspectives on the value of student-led activities}

At each case study school, we talked to a group of student leaders. The activities that they were the most proud of, and engaged in, were those which they or other students led, or which enabled them to "take action". Being a student leader was empowering for these students, and they were acutely conscious of their position as role models. 


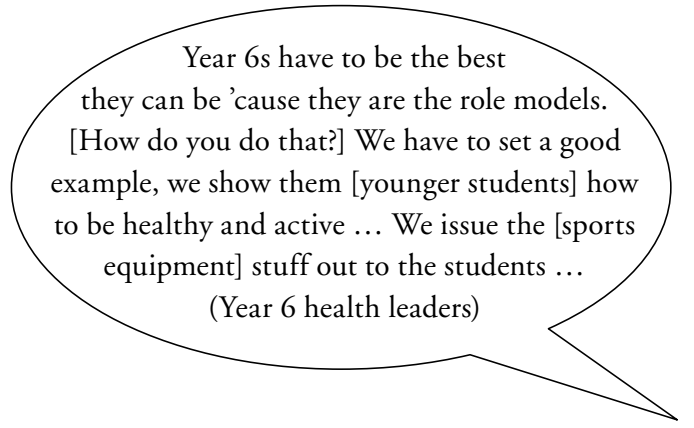

The students we talked to all had a good understanding of healthy choices, and could describe how they had changed aspects of their behaviour at school to better model healthy behaviours. A number were also transferring this knowledge to their home. They also had a clear sense of school priorities, actions and guidelines relating to health. All the students valued their school's focus on health and wellbeing, with many describing their school as "healthy" or "very active".

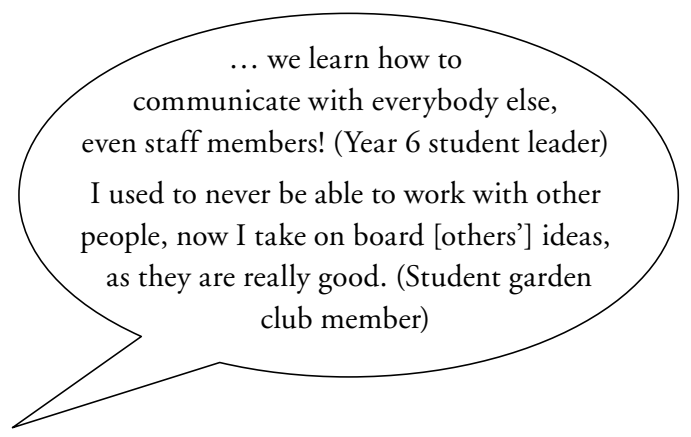

As well as increasing their knowledge about healthy lifestyle choices, students described how they were gaining valuable life skills and competencies from their work as a member of a student-led team. These included understanding of others' perspectives, critical thinking, consultation, planning, teamwork, communication and leadership skills. Thus, these activities were supporting students to build the key competencies outlined in the revised curriculum.

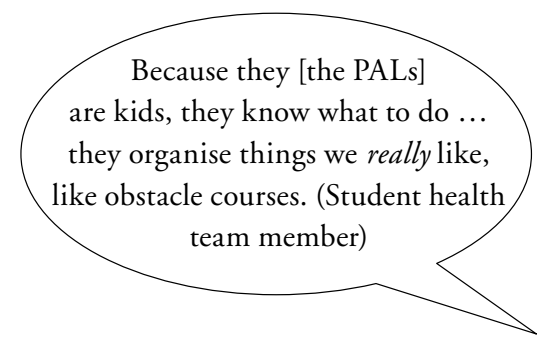

Students considered that student health teams and PALs were more successful than teachers in organising activities that had meaning for students, and which encouraged wider participation by all students.

\section{School staff perspectives on the value of student-led activities}

Offering students an increasing range of leadership opportunities was assisting school leaders and teachers to see the value of placing students in the driving seat. Teachers in the case study schools were surprised at the quality of students' suggestions and their skills in organising and promoting health-related events. They also observed that students sometimes had better ideas than staff about how to tap into their peers' interests and passions. School staff could also see how empowered and engaged students were as they took action to make a positive difference to the health environment at their school. Some commented on the changes they observed in students who previously had been disengaged or reluctant to participate in school activities. Teachers also observed that "learning by doing" enabled students to turn their classroom content learning into a concrete action, which made this learning more meaningful. Like students, teachers also considered these experiences gave students many opportunities to demonstrate and build the key competencies. As a result of these reflections, some staff were starting to question who had the power in the school environment and to see that many of the decisions they made, and the activities they ran, could include more space for active student involvement. This was leading staff to set up more opportunities for student input.

\section{What did the survey findings show about benefits for students?}

The data from the case study schools suggested that offering a range of student-led opportunities is related to a number of benefits for students, from increased wellbeing and ability to make healthy choices, to increased retention of health knowledge and opportunities to build the key competencies. The data from a student survey also supported these findings. This showed that students at FiS schools had more opportunities to give input into school activities than students at a group of comparison schools. In addition, these data showed that those students who had more input were also more likely to like being at school, have a higher awareness of the importance of healthy behaviours and maintain positive health-related attitudes and behaviours over time.

It seems that student-led opportunities are contributing to the creation of a "protective climate" around students. It is possible that this climate will impact on students' longer term health and education outcomes. Longitudinal studies show that participation in volunteer activities (that is, activities similar to health or Enviroschools teams) and sports teams are "protective 
factors" that are associated with lower engagement in future risky health behaviours (Health Sponsorship Council, 2005). Studies also show that engagement at school (like that experienced by the students in these teams) is associated with improved academic success (Wylie, Hipkins, \& Hodgen, 2008).

\section{What are the challenges of enabling student-led actions?}

Although there were many benefits from enabling students to drive health-related actions at school, staff also experienced some challenges. Sharing decision-making power with students can require a mindshift for teachers and school leaders, as they acknowledge the expertise that students can bring to the table. In addition, studentled activities do not mean a hands-off role for teachers. In fact, their role can be more complex as they act as a facilitator and resource person. Some teachers found they needed to assist students to prioritise tasks that would be manageable, so that students were able to see their plans through and therefore experience success. At some schools, student teams met during class or lunchtime with school staff or external facilitators. If this took teachers out of the classroom, it could be difficult for them to sustain.

The Health Promoting Schools approach suggests that schools develop a team of activists. These teams tend to initially work outside of the classroom programme. It is intended that this style of working will eventually spread across the whole school, including within the classroom programme. The need for all students to actively engage in health promotion is one of the key concepts underpinning the Health and PE learning area. For this to occur in a systematic way, a focus on health promotion actions needs to be an explicit part of curriculum practice and planning. Some case study schools were evolving models of student action that were located within the classroom programme. At one school, as well has having a multi-year-level health team, senior and junior classes also planned different actions related to their school-wide health focus. For example, the senior classes conducted a school survey about lunch-box food and wrappings. The results fed into a zero-waste week with a healthy eating focus. At another school, as part of a technologybased unit, a class designed and made a water catchment device to provide water for the school garden (which was not located near a tap), and another class had three health teams all working on different projects they had nominated to improve the school health environment.

Other schools were evolving models of student action which enabled more students to participate. Some school leaders were strategic about ensuring all senior students had opportunities to lead or be an active member of a school team or extracurricula group (thus ensuring that all were able to show their strengths and had a strong connection to at least one school-based activity). Rather than locating most of the leadership opportunities in the senior school, other schools were starting to explore ways of buddying junior students with senior teams to ensure that younger students had opportunities to develop leadership capabilities over time.

Although the work of student teams was not necessarily part of core classroom work, at all of the case study schools the work of these teams was part of a bigger picture. Students' plans were related to recent curriculum topics, school-wide health or environmental themes or schoolwide community events. In general, teachers considered students' actions were the most successful when they were clearly linked to school-wide themes or curriculum topics. They also considered that students' learning was supported by the increased coherence between classroom and schoolwide healthy-choice messages.

\section{What next?}

This article only touches on some of the varied healthrelated projects students are currently designing and carrying out in schools. This information suggests that student-led actions relating to the Health and PE learning area offer many rich opportunities for students to meet the vision of "confident, connected, actively involved, lifelong learners" in The New Zealand Curriculum (Ministry of Education, 2007b).

Many primary schools are currently moving towards using integrated or inquiry approaches to structure students' learning. The idea of working towards taking action also underpins some, but not all, of the integrated and inquiry learning approaches that are commonly used. To ensure that inquiry approaches have a good fit with the intent suggested in this article, it is important that students have input into the action which is decided on, and that this action makes a meaningful difference to the school environment - that is, it moves students beyond just being a "seeker" of knowledge (for example, as commonly demonstrated through the display of content knowledge in the form of a poster, report or presentation) towards also being a "user and creator of knowledge" as students engage in an active act of health promotion. In the Health and PE learning area, discipline-specific approaches, which overlap with integrated and inquiry learning approaches, are available. One example is the Action Competence Learning Process developed by Gillian Tasker (Ministry of Education, 2004).

For schools wanting to increase their focus on student-led actions, there are groups which provide 


\section{STUDENTS AND CURRICULUM}

support, such as Health Promoting Schools advisers ${ }^{3}$ and Active Schools facilitators. ${ }^{4}$ There are also a number of resources available to support schools. One is Key Competencies: Exploring the Potential of Participating and Contributing (Bolstad, Roberts, Boyd, \& Hipkins, 2009). This resource includes an audit tool designed to encourage school staff to review and reflect on the range of opportunities students have to actively participate at school. Other resources include Food and Nutrition for Healthy, Confident Kids (Ministry of Education, 2007a), Growing Leaders from SPARC (2009), 5 the Curriculum in Action series on Te Kete Ipurangi (TKI) (in particular: Making Meaning: Making a Difference ${ }^{6}$ ) and the Keepin' it Real guide (Ministry of Youth Development, 2003), Making it Happen (Ministry of Youth Development, 2005) and other resources from the Ministry of Youth Development.?

The following reflection questions are designed as a starting point for staff to review current views and practices relating to student involvement in decision making and action:

- Is it possible for all school activities to have some form of student input? Is there any aspect of school life that students could not contribute to?

- At our school, how do we find out about what students really need, want or enjoy in relation to their health and wellbeing? Are there new ways we can find out about students' needs and interests?

- What do we currently do well about encouraging students to take action to improve their and others' health and wellbeing? Are there new ways we could involve students in school actions and decisions?

\section{Acknowledgements}

The Healthy Futures study was conducted by researchers from the New Zealand Council for Educational Research and Health Outcomes International, and involved the input of many students, school staff, parents and whānau and health promoters. The Healthy Futures study was funded by the Ministry of Health.

\section{Notes}

1 This model is also a key underpinning of Te Aho Matua, the foundation document for kura kaupapa Māori.

2 See the companion article for an example of a health promotion process.

3 http://www.hps.org.nz

4 http://www.sparc.org.nz/partners-and-programmes/ regional-sports-trusts/regional-sports-trusts-lists

5 http://www.sparc.org.nz/education/growing-leaders

6 http://www.tki.org.nz/r/health/cia/make_meaning/ index_e.php
7 http://www.myd.govt.nz/Publications/ YouthDevelopment/keepinitreal.aspx

\section{References}

Aitken, G. (2006). Signalling shifts in meaning: The experience of social studies curriculum design. Curriculum Matters, 2, $6-25$.

Bolstad, R., Roberts, J., Boyd, S., \& Hipkins, R. (2009). Key competencies: Exploring the potential of participating and contributing. Wellington: NZCER Press.

Boyd, S., \& Moss, M. (2009). The changing face of Fruit in Schools: The 2008 case studies: Final Healthy Futures evaluation report. Unpublished report to the Ministry of Health.

Health Sponsorship Council. (2005). Reducing smoking initiation literature review. Wellington: Author.

Lister-Sharp, D., Chapman, S., Stewart-Brown, S., \& Sowden, A. (1999). Health promoting schools and health promotion in schools: Two systematic reviews. Health Technology Assessment, 3, 1-207.

Ministry of Education. (1999). Health and physical education in the New Zealand curriculum. Wellington: Learning Media. Available at: http://www.tki.org.nz/r/health/curriculum/ statement/hpe_statement.pdf

Ministry of Education. (2004). The curriculum in action: Making meaning: Making a difference. Wellington: Learning Media.

Ministry of Education. (2007a). Food and nutrition for healthy, confident kids. Wellington: Learning Media.

Ministry of Education. (2007b). The New Zealand curriculum. Wellington: Learning Media.

Ministry of Youth Development. (2003). Keepin' it real: A resource for involving young people. Wellington: Author.

Ministry of Youth Development. (2005). Making it happen ... Strengthening youth development in schools. Wellington: Author.

SPARC. (2009). Facilitator's guide: Growing leaders of the future. Retrieved from Sport and Recreation New Zealand: http:// www.sparc.org.nz/education/growing-leaders/growingleaders-resources

Tasker, G. (2004). Health education: Contributing to a just society through curriculum change. In A. O'Neill, J. Clark, $\&$ R. Openshaw (Eds.), Reshaping culture, knowledge and learning? Policy and content in the New Zealand curriculum framework: Volume one (pp. 203-223). Palmerston North: Dunmore Press.

Wylie, C., Hipkins, R., \& Hodgen, E. (2008). On the edge of adulthood: Young people's school and out-of-school experiences at 16. Wellington: Ministry of Education.

SALLY BOYD is a senior researcher at the New Zealand Council for Educational Research.

Email: Sally.Boydळnzcer.org.nz 